\title{
FATORES ECOFISIOLÓGICOS QUE AFETAM O COMPORTAMENTO DO MILHO EM SEMEADURA TARDIA (SAFRINHA) NO BRASIL CENTRAL ${ }^{1}$
}

\author{
F.O.M. DURÃES ${ }^{2}$; P.C. MAGALHÃES ${ }^{2}$; J.D. COSTA $^{3}$; A.L. FANCELLI ${ }^{3}$ \\ ${ }_{3}^{2}$ CNPMS/EMBRAPA - C.P. 151 - CEP: $35701-970$ - Sete Lagoas, MG \\ ${ }^{3}$ Depto. de Agricultura da ESALQ/USP - C.P. 9 - CEP: 13418-900 - Piracicaba, SP
}

RESUMO: O presente trabalho teve por objetivo avaliar as relaçōes entre fonte de assimilados e grảo-dreno, bem como o comportamento de fatores morfo-físiologicos que limitam o rendimento de gräos em plantas de milho de diferentes ciclos (normal, precoce e superprecoce), cultivadas em semeadura tardia (safrinha), com trés densidades (33 mil, 55 mil e 77 mil plantas/ha). Verificou-se a eficiencia de híbridos de millho quanto à duração do crescimento e rendimento, nas fases vegetativa e reprodutiva. Os rendimentos em grảos variaram entre os híbridos e entre as densidades e foram significativamente superiores nas maiores densidades de cultivo, para os três hibridos avaliados. Valores máximos de índice de área foliar, dentro de híbrido, resultaram em maiores rendimentos de grấos e contribuiram para explicar a variaçăo do acímulo de matéria seca total e do grảo. Todos os híbridos tiveram o enchimento de grãos incompleto, indicando inadequada oferta de assimilados durante essa fase, principalmente para o hibrido superprecoce. Isto sugere que a oferta foi inferior a capacidade de armazenamento na espiga e, nesse caso, além do rendimento de grãos, outros 6́rgäos vegetativos ficaram prejudicados em sen desenvolvimento. As condiçöes ambientais de cultivo de safrinha são sub6timas para o desenvolvimento do milho, principalmente para os hibridos com caracteristicas e comportamento de precocidade acentuada.

Descritores: Zea mays L., hibridos, ciclos, densidade, safrinha, grăo-dreno.

\section{ECOPHYSIOLOGICAL FACTORS AFFECTING MAIZE BEHAVIOUR OF LATE SUMMER PLANTING IN CENTRAL BRAZIL}

ABSTRACT: The objective of this work was to evaluate the source-sink relationships, as well as the effects of morphophysiological factors that limit the grain yield of maize plants of different cycles (normal, early and very early) planted in late summer ("safrimha"). This trial included three plant populations (33, 55 and 77 thousand plants/hectare). Hybrid efficiencies related to duration of growth and yield were evaluated, in the vegetative and reproductive phases. The grain yield varied among hybrids and populations, and the best yields were found in the highest plant population for all hybrids. The maximum values for leaf area index within hybrids resulted in high grain yields and contributed greatly to total dry matter accumulation in the plant and grain. All the hybrids had incomple grain filling, which indicates low offer of assimilates during this stage, especially for very early hybrids. This suggests that the source was lower than the capacity of the sink and in this case, besides grain yield, other vegetative parts were injured in their development. Environmental conditions for cultivating in late summer are not the best for the development of the maize plant, mainly for hybrids of very early cycle.

Key Words: Zea mays L., hybrids, cycles, density, source-sink.

\section{INTRODUÇÃO}

As opções de culturas economicamente viáveis no Brasil Central para o período de fevereiro a agosto estão restritas a poucas espécies, como o feijão-da-seca, amendoim e cereais de inverno. Recentemente a cultura do milho vem se tornando uma alternativa de cultivo para o mencionado período.

Por se tratar de cultivo fora de época e de grande risco, muitos produtores de milho safrinha ainda usam medidas tecnologicas inadequadas, acarretando baixas produtividades. A semeadura de grãos provenientes da segunda geração dos

${ }^{1}$ Parte da Tese de Doutorado do primeiro Autor apresentado à - ESALQ/USP 
híbridos cultivados na safra normal e o aproveitamento da adubação residual da cultura anterior são práticas que devem ser substituídas para o aumento de produtividade do milho safrinha. Entretanto, ainda, carece de informações adequadas sobre a recomendação de híbridos e variedades de milho préferenciais para cada região, para essa época de semeadura (Gerage \& Bianco, 1987).

Fatores ambientais que limitam a adaptação de híbridos de milho interferem, de forma significativa, no rendimento de grãos. Esse rendimento tende a ser limitado por processos que influenciam a oferta de assimilados no período de enchimento de grãos e/ou processos que controlam o desenvolvimento do grão-dreno. Diferenças de rendimento de grãos entre genótipos de milho de diferentes ciclos são, com frequência, examinados em termos da relação entre produção total (palhada e grãos) e a partição da matéria seca para o grão (IC, indice de colheita), Donald \& Hamblin (1976). Segundo Durães et al. (1993), embora IC seja um índice de construção prática, sua utilização para comparar a performance agronômica de genótipos de milho não favorece a identificação de respostas fisiológicas limitantes do rendimento.

O transporte dos produtos fotossintetizados obedece a padrões bem estabelecidos, dependendo da morfologia da planta. No milho, o mais intenso sítio de consumo dos produtos de fotossíntese ocorrè durante a fase reprodutiva, é representado pelos grãos em processo de rápido crescimento (Allison \& Watson, 1966).

0 eficiente transporte de materiais, produzidos e acumulados nas folhas, em direção aos grãos em formação, é de grande importância para garantir alta produção.

Características importantes de planta, na determinação da eficiência de produção de grãos, são a duração e extensão da área foliàr que permanece fisiologicamente ativa após a emergência da espiga. Assim, a produtividade da planta de milho pode ser correlacionada com a duração da área foliar (Daynard et al., 1971). Entretanto, genótipos de milho podem apresentar diferentes características de produtividade de grãos em função do tempo ocorrido desde a antese até a fase de senescência das folhas.

A maior eficiência fotossintética dos genótipos de milho altamente produtivas é decorrência mais pelo incremento da intensidade fotossintetica do que pelo aumento da capacidade fotossintética, que está associada com a superfície total dos órgãos que realizam fotossíntese. Produções crescentes estão associadas com a obtenção de valores mais elevados de intensidade fotossintética e a um transporte mais eficiente dos produtos fotoassimilados para o órgão colhido grãos (Tollenaar \& Daynard, 1977).

Os inúmeros fatores e processos que atuam concorrentemente para o rendimento de grãos em cultivos de milho são relacionados com a interceptação de luz pela cobertura vegetal da cultura, eficiência metabólica das plantas, eficiência de translocação de fotossintatos das folhas e colmos para os grãos em crescimento e capacidade de dreno. As relações de fonte e de dreno são função de condições ambientais (Wilson et al., 1973; Tollenaar, 1977).

A importância relativa desses fatores e processos não $\epsilon$ amplamente conhecida para os diferentes genótipos, sobretudo em condições de manejo distintas daquelas nas quais cada um foi selecionado pelo melhoramento genético. Torna-se importante identificá-los, a fim de que os rendimentos de cada genótipo possam ser incrementados, em relação aos seus níveis atuais.

Entender a natureza do acúmulo de materia seca durante a estação de crescimento, bem como a partição da matéria seca para o grão e outros componentes da planta pode direcionar para o incremento do rendimento de grãos, através do melhoramento (genético e do manejo) de plantas.

Objetivando-se avaliar as relações entre fonte de assimilados e grão-dreno, bem como o comportamento de fatores morfo-fisiológicos que limitam o rendimento de grãos em plantas de milho de diferentes ciclos (normal, precoce e superprecoce), em semeadura tardia, foi conduzido um experimento com três densidades de cultivo.

\section{MATERIAL E MÉTODOS}

Os estudos foram realizados em Piracicaba, SP, no Campus da USP/ESALQ, no período de 13 de fevereiro a 23 de julho de 1992, sob condições de campo, em solo classificado como Terra Roxa estruturada eutrófica A moderado textura argilosa/ muito argilosa (Vidal Torrado \& Sparovek, 1993).

As condições climáticas no período de realização do experimento são apresentadas na Figura 1 (Dados obtidos no Posto Agrometeorológico do Departamento de Física e Meteorologia da ESALQ/USP). A radiação global

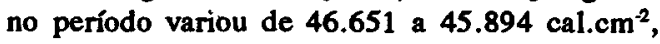




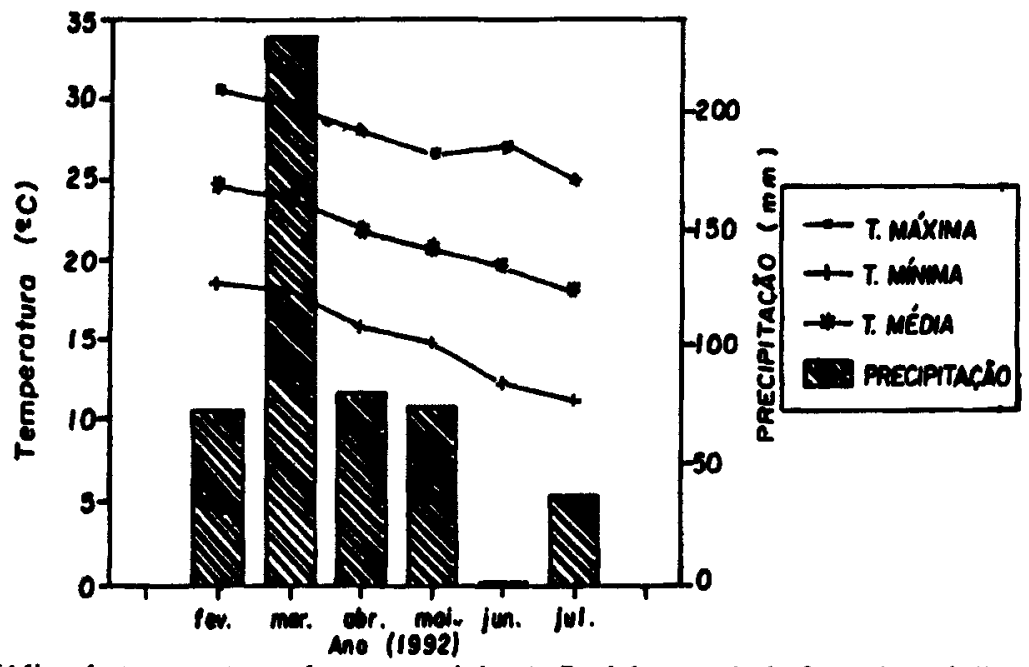

Figura 1 - Médias de temperaturas do ar e precipitaçãofluvial mensal, de fevereiro a julho de 1992, USP/ ESALQ, Piracicaba, S.P. 1994.

entre os tratamentos (considerando da semeadura até o máximo acúmulo de matéria seca dos grãos). Para o cômputo de Graus-Dia (GD) os períodos estudados foram: da semeadura ao início do período de enchimento de grãos (iPEG) e, iPEG ao ponto de maturidade fisiológica (PMF). O método de Brown, citado por Aspiazú (1971), foi empregado para o cálculo de $G D$, utilizando-se a fórmula:

$$
\mathrm{GD}=\mathrm{a}\{(\mathrm{T} \min +\mathrm{T} \max ) / 2\}-\mathrm{T} \text { base }
$$

onde,

$$
\begin{aligned}
& T \min =10 \text { para } T \min <10^{\circ} \mathrm{c} ; \\
& T \max =30 \text { para } T \max >30^{\circ} \mathrm{c} ; \\
& T \text { base }=10^{\circ} \mathrm{c}
\end{aligned}
$$

Foram utilizados três hỉbridos comerciais de milho (TABELA 1), representativos de diferentes ciclos de cultivo (c1- normal, c2- precoce e c3superprecoce), cultivados em três densidades de plantas (d1- 33 mil, d2- 55 mil, d3- 77 mil plantas/ ha).

O experimento foi conduzido no delineamento de blocos casualizados, com parcelas subdivididas, com quatro repetições. As parcelas foram constituídas por um fatorial $3^{2}$, envolvendo três híbridos e três densidades de plantio.

A parcela experimental foi composta por cinco linhas de $16,0 \mathrm{~m}$ de comprimento, espaçadas $0,90 \mathrm{~m}$ entre si. As duas linhas externas serviram como bordaduras.

As amostragens periódicas de plantas, em número de dez, foram realizadas em trés plantas representativas da fase da cultura na parcela e colhidas das três fileiras centrais, em intervalos de
14 dias. A primeira amostragem foi efetuada no $21^{\circ}$ dia após a semeadura (DAS) e coincidente com o desbaste de plântulas, para ajuste das densidades de plantas programadas nos tratamentos.

Durante o ciclo das plantas, foram efetuadas avaliações de características morfo-fisiológicas, nas etapas vegetativa, reprodutiva e de formação dos grãos. Foram determinadas altura da planta (AP) $e$ o número de folhas por planta (NFLE), área foliar (AF), matéria seca da planta (MST) e por órgão (colmo + bainha, limbo foliar, pendão, espiga = brácteas + sabugo + grãos) e, produção por área (g MS/ $\mathrm{m}^{2} ; \mathrm{kg} / \mathrm{ha}$ de grão, a $13 \%$ de umidade, e kg/ ha de palhada). Os componentes do rendimento (média de 5 espigas) foram determinados, por tratamento, em: comprimento da espiga, cm (CE); diâmetro da espiga, cm (DE); número de fileiras por espiga (NF/E); quantidade de grãos por fileira por espiga ( $Q G / F / E)$; quantidade total de grãos por espiga (QTG/E); número de grãos por metro quadrado de terreno (híbrido $x$ densidade) (NG/ $\mathrm{m}^{2} / \mathrm{T}$ ).

Os dados coletados foram submetidos à análise de variância. Diferenças de médias entre tratamentos foram comparadas pelo teste de Duncan, ao nível de $5 \%$ de probabilidade. Também foi testada a regressão ajustada aos dados de matéria seca total e de grãos.

Obteve-se ainda, $o$ indice de área foliar (IAF), produtividade biológica (PB), taxa de crescimento da cultura (TCC) e taxa de crescimento do grão (TCG). 


\section{RESULTADOS E DISCUSSÃo}

A distribuição relativa sazonal de matéria seca em híbridos de milho de diferentes ciclos, em três densidades de plantio, $\varepsilon$ apresentada por híbrido, na Figura $2(a, b, c)$. A variação na densidade de semeadura resultou em alterações morfológicas e fisiológicas da planta (TABELAS 2 e 3). Observou-se uma compensação por área de terreno, resultando em uma tendência de maiores acúmulos de matéria seca total e de grãos, nas maiores densidades de cultivo, para os três híbridos.

Os dados da TABELA 2 mostram que, aos 77 DAS, os percentuais do acúmulo de matéria seca dos grãos foram pequenos, em relação ao total da matéria seca; portanto, nesse estudo, o período de enchimento de grãos (PEG) foi de 77 DAS ao ponto de maturidade fisiológica (PMF), representando mais que $98 \%$ do enchimento de grãos em todos os tratamentos. Os valores máximos de matéria seca total $\left(1.111 ; 1.654 ; 1.844 \mathrm{~g} / \mathrm{m}^{2}\right)$, para cldl, cld2 e cld3, respectivamente, foram atingidos no período entre duas semanas antes/até à maturidade; de $\left(1.234 ; 1.648 ; 2.159 \mathrm{~g} / \mathrm{m}^{2}\right.$, para c2d1, c2d2 e c2d3, respectivamente, atingidos na maturidade; $e$, de (776; $1.151 ; 1.423 \mathrm{~g} / \mathrm{m}^{2}$, para $\mathrm{c} 3 \mathrm{dl}$, c3d2 e c3d3, respectivamente, atingidos no período compreendido entre quatro semanas antes/até à maturidade.

A análise de variância dos dados de matéria seca apresenta diferença significativa, a nível de $1 \%$ de probabilidade para o teste de F, para os fatores híbrido e densidade; entretanto, não foi significativo para a interação híbrido $\mathrm{x}$ densidade.

$O$ acúmulo de matéria seca total foi maior no híbrido normal, menor no superprecoce e intermediário no precoce.
Hanway \& Russell (1969) obtiveram resultados similares, onde concluiram que o maior acúmulo de matéria seca nos genótipos tardios devese ao fato de possuírem maior ciclo, já que os indices de crescimento foram semelhantes. Entretanto, Goldsworthy \& Colegrove (1974) e Goldsworthy et al. (1974), em condições distintas, encontraram que genótipos de milho tropical acumulam mais matéria seca nas partes vegetativas da planta que em partes reprodutivas após antese, e produziu menos que genótipos de milho temperado.

As condições ambientais de cultivo de safrinha são subótimas para o desenvolvimento do milho em relação ao cultivo de primavera-verão, o que implica em considerar importante a época de semeadura, por afetar principalmente o ciclo da cultura e o rendimento de grãos. Experimentos tem mostrado variação na estabilidade do rendimento de grãos de diferentes genótipos, em função do retardamento da semeadura; entretanto, os resultados não são conclusivos.

Na TABELA 3 são apresentados, por tratamento, os dados de altura de planta, número de folhas com limbo completamente expandido e área foliar verde.

Os coeficientes das equações ajustadas aos dados observados de área foliar, matéria seca total e de grão, em função do tempo e os respectivos coeficientes de determinação estão apresentados na TABELA 4.

Para todos os tratamentos, nas condições do experimento, a equação que se ajustou adequadamente aos dados de área foliar foi o polinômio de $2^{\circ}$ grau, com $R^{2}$ variando de 0,82 a 0,96 . Os dados de área foliar dos híbridos apontam, nas três densidades, para comportamentos

TABELA 1 - Características dos cultivares de milho de diferentes ciclos.

\begin{tabular}{|c|c|c|c|c|c|c|}
\hline \multicolumn{3}{|c|}{ Cultivar } & \multirow{2}{*}{$\begin{array}{l}\text { Peso de } \\
1000 \\
\text { grãos (g) }\end{array}$} & \multicolumn{2}{|c|}{ Ciclo (dias) } & Peso de \\
\hline $\begin{array}{c}\text { Identificação } \\
\text { (ciclo) }\end{array}$ & Nome Comercial & Tipo & & $\begin{array}{l}\text { Florescimento } \\
\text { masculino }\end{array}$ & Maturação & $\begin{array}{l}\text { grãos } \\
(\mathrm{kg} / \mathrm{ha})\end{array}$ \\
\hline c1-normal & XL 380 (BRASKALB) & H.T. & 337,80 & 66 & - & $6.411^{1}$ \\
\hline c2-precoce & BR 201(EMBRAPA) & H.D. & 322,17 & 62 & 130 & $6.558^{2}$ \\
\hline c3-superprecoce & P 3072 (PIONEER) & H.S.m. & 267,20 & 56 & - & $6.731^{2}$ \\
\hline
\end{tabular}

\footnotetext{
'Média de Ensaio Regional Milho. IAPAR, 1990/91. Londrina, PR.

${ }^{2}$ Média de Ensaio Nacional Milho. Ano Agrícola 1990/91. SP.

HT, híbrido triplo; HD, híbrido duplo; HSm, híbrido simples modificado.
} 
TABELA 2 - Matéria seca da planta total e do grão, relativa aos perfodos de máximo acúmulo (máx.), no ponto de maturidade fisiológica (PMF) e aos 77 dias ap6s a semeadura (DAS), de cultivares de milho de diferentes ciclos, em tres densidades de cultivo de safrinha. USP/ESALQ, Piracicaba, SR. 1994.

\begin{tabular}{|c|c|c|c|c|c|c|c|c|c|}
\hline \multirow{3}{*}{\multicolumn{2}{|c|}{$\frac{\text { Tratamento }}{\text { cultivardensidade }}$}} & \multicolumn{4}{|c|}{ Materia Seca Total } & \multicolumn{3}{|c|}{ Materia Seca do Grão } & \multirow{3}{*}{$\%$} \\
\hline & & \multicolumn{2}{|c|}{ máx. } & \multicolumn{2}{|c|}{ PMF 77 DAS } & \multicolumn{2}{|c|}{$m a x .=P M F$} & \multirow{2}{*}{$\frac{77 \mathrm{DAS}}{\mathrm{g} / \mathrm{m}^{2}}$} & \\
\hline & & DAS & $g / m^{2}$ & x & & DAS & $g / m^{2}$ & & \\
\hline \multirow[t]{4}{*}{$X L 380$} & 33 & 133 & 1.111 & 97,7 & 42,1 & 147 & 476 & 2,3 & 0,48 \\
\hline & 55 & 133 & 1.654 & 86,4 & 46,2 & 147 & 587 & 2,0 & 0,34 \\
\hline & 77 & 147 & 1.844 & 100,0 & 47,3 & 147 & 781 & 3,2 & 0,41 \\
\hline & Média & 137,7 & 1.536 & 94,7 & 45,2 & 147 & 614 & 2,5 & 0,41 \\
\hline \multirow[t]{4}{*}{ BR 201} & 33 & 133 & 1.234 & 100,0 & 42,9 & 133 & 495 & 5,5 & 1,10 \\
\hline & 55 & 133 & 1.648 & 100,0 & 34,3 & 133 & 672 & 5,1 & 0,76 \\
\hline & 77 & 133 & 2.159 & 100,0 & 45,1 & 133 & 910 & 5,4 & 0,59 \\
\hline & MÉdia & 133 & 1.680 & 100,0 & 40,8 & 133 & 692 & 5,3 & 0,82 \\
\hline \multirow[t]{4}{*}{ P 3072} & 33 & 119 & 776 & 97,1 & 58,2 & 147 & 293 & 4,9 & 1,66 \\
\hline & 55 & 119 & 1.151 & 87,1 & 53,2 & 147 & 426 & 7,8 & 1,82 \\
\hline & 77 & 147 & 1.423 & 100,0 & 53,8 & 147 & 557 & 11,7 & 2,10 \\
\hline & MEdia & 128,3 & 1.116 & 94,7 & 55,1 & 147 & 422 & 8,1 & 1,86 \\
\hline
\end{tabular}

TABELA 3 - Altura de planta (AP), número de folhas com limbo foliar completamente expanuido (NFLE) e área foliar verde (AF), médias por planta, de cultivares de milho de diferentes ciclos, em tres densidades de cultivo de safrinha. USP/ESALQ, Piracicaba, SP. 1994.

\begin{tabular}{|c|c|c|c|c|c|c|c|}
\hline \multicolumn{2}{|c|}{ Tratamento } & \multicolumn{2}{|c|}{$\operatorname{AP}(\mathrm{cm})$} & \multicolumn{2}{|c|}{ NFLE } & \multicolumn{2}{|c|}{$\operatorname{AF}\left(\mathrm{cm}^{2}\right)$} \\
\hline cultivar & $\begin{array}{c}\text { densidade } \\
\text { (1000 } \text { plantas/ha) }\end{array}$ & 77 DAS & PMF & 77 DAS & PMF & 77 DAS & PMF \\
\hline XL 380 & $\begin{array}{l}33 \\
55 \\
77\end{array}$ & $\begin{array}{l}192,3 \mathrm{ab} \\
203,5 \mathrm{a} \\
189,0 \mathrm{abc}\end{array}$ & $\begin{array}{l}197,8 \mathrm{a} \\
208,5 \mathrm{a} \\
209,8 \mathrm{a}\end{array}$ & $\begin{array}{l}13,8 \mathrm{abc} \\
14,3 \mathrm{ab} \\
13,8 \mathrm{abc}\end{array}$ & $\begin{array}{c}13,0 \mathrm{a} \\
13,0 \mathrm{a} \\
13,0 \mathrm{a}\end{array}$ & $\begin{array}{l}6.849,0 \mathrm{ab} \\
7.338,7 \mathrm{al} . \\
6.738,6 \mathrm{ab}\end{array}$ & $\begin{array}{l}776,1 \mathrm{ab} \\
306,9 \mathrm{a} \\
272,3 \mathrm{~b}\end{array}$ \\
\hline BR 201 & $\begin{array}{l}33 \\
55 \\
77\end{array}$ & $\begin{array}{l}202,0 \mathrm{a} \\
196,5 \mathrm{ab} \\
203,0 \mathrm{a}\end{array}$ & $\begin{array}{l}205,0 \mathrm{a} \\
204,0 \mathrm{a} \\
204,5 \mathrm{a}\end{array}$ & $\begin{array}{l}14,0 \mathrm{abc} \\
14,0 \mathrm{abc} \\
14,8 \mathrm{a}\end{array}$ & $\begin{array}{l}13,0 \mathrm{a} \\
12,8 \mathrm{ab} \\
13,5 \mathrm{a}\end{array}$ & $\begin{array}{l}6.898,5 a b \\
6.784,2 a b \\
6.646,5 a b\end{array}$ & $\begin{array}{c}849,3 \mathrm{ab} \\
290,9 \mathrm{~b} \\
177,9 \mathrm{~b}\end{array}$ \\
\hline P 3072 & $\begin{array}{l}33 \\
55 \\
77\end{array}$ & $\begin{array}{l}166,3 \mathrm{~d} \\
172,3 \mathrm{~cd} \\
181,8 \mathrm{bcd}\end{array}$ & $\begin{array}{c}168,8 \mathrm{~b} \\
178,3 \mathrm{~b} \\
183,0 \mathrm{~b}\end{array}$ & $\begin{array}{l}13,3 \mathrm{bc} \\
14,0 \mathrm{abc} \\
13,0 \mathrm{c}\end{array}$ & $\begin{array}{l}10,8 \mathrm{c} \\
11,3 \mathrm{bc} \\
11,3 \mathrm{bc}\end{array}$ & $\begin{array}{l}6.203,5 \text { bc } \\
5.476,1 \text { cd } \\
5.103,3 d\end{array}$ & $\begin{array}{r}0,0 \text { b } \\
0,0 \text { b } \\
15,7 \text { b }\end{array}$ \\
\hline CV (\%) & & 6,33 & & 5,03 & & 10,06 & \\
\hline
\end{tabular}

Na coluna, médias seguidas da mesma letra não diferem entre si, a $5 \%$ de probabilidade, pelo teste de Duncan. 
TABELA 4 - Coeficientes das equações que descrevem a área foliar, matéria seca total e matéria seca do grão em função do tempo e respectivos coeficientes de determinação $\left(R^{2}\right)$, de cultivares de milho de diferentes ciclos, em três densidades de cultivo de safrinha. USP/ESALQ, Piracicaba, SP. 1994.

\begin{tabular}{|c|c|c|c|c|}
\hline \multirow[t]{2}{*}{ cultivar } & \multirow[t]{2}{*}{ termos } & \multicolumn{3}{|c|}{ densidade (1000 plantas/ha) } \\
\hline & & 33 & 55 & 77 \\
\hline & --1 & ------área fo & planta) ${ }^{1}$ & - - - - \\
\hline \multirow[t]{4}{*}{ XL 380} & $a=$ & $-2,241812$ & $-3,662002$ & $-4,745199$ \\
\hline & $\mathbf{b}=$ & 0,1044931 & 0,172967 & 0,2305594 \\
\hline & $c=$ & $-6,049011 E-04$ & $-1,0072668 \mathrm{E}-03$ & $-1,36843 E-03$ \\
\hline & $\mathbf{R}^{2}=$ & 0,95 & 0,96 & 0,94 \\
\hline \multirow[t]{4}{*}{ BR 201} & $\mathbf{a}=$ & $-2,145536$ & $-3,316037$ & $-4,275737$ \\
\hline & $b=$ & 0,1062498 & 0,1663918 & 0,2183645 \\
\hline & $\mathrm{c}=$ & $-6,369821 E-04$ & $-1,331844 \mathrm{E}-03$ & $-1,331844 \mathrm{E}-03$ \\
\hline & $\mathbf{R}^{2}=$ & 0,91 & 0,91 & 0,88 \\
\hline \multirow{5}{*}{ P 3072} & $a=$ & $-1,605158$ & $-2,4888$ & $-3,165558$ \\
\hline & $b=$ & 0,0402036 & 0,1318521 & 0,1737994 \\
\hline & $c=$ & $-5,214518 \mathrm{E}-04$ & $-8,143174 \mathrm{E} 04$ & $-1,086174 \mathrm{E}-03$ \\
\hline & $\mathbf{R}^{2}=$ & 0,82 & 0,87 & 0,83 \\
\hline & -1 & - - - matéri & $\mathrm{al}\left(\mathrm{g} / \mathrm{m}^{2}\right)^{2}-\ldots$ & ----- \\
\hline \multirow[t]{4}{*}{ XL 380} & $a=$ & 1.161 & 1.604 & 1.892 \\
\hline & $\mathrm{b}=$ & 155,681 & 134,590 & 76,878 \\
\hline & $\mathbf{k}=$ & 0,057736596 & 0,05828234 & 0,05165149 \\
\hline & $\mathbf{R}^{2}=$ & 0,95 & 0,94 & 0,93 \\
\hline \multirow[t]{4}{*}{ BR 201} & $a=$ & 1.166 & 1.551 & 2.164 \\
\hline & $b=$ & 131,611 & 201,274 & 112,307 \\
\hline & $\mathrm{k}=$ & 0,05797175 & 0,06489967 & 0,05540982 \\
\hline & $\mathbf{R}^{2}=$ & 0,94 & 0,96 & 0,95 \\
\hline \multirow[t]{4}{*}{ P 3072} & $a=$ & 730 & 1.081 & 1.341 \\
\hline & $b=$ & 320,960 & 199,092 & 168,821 \\
\hline & $\mathrm{k}=$ & 0,08040832 & 0,07294096 & 0,0716757 \\
\hline & $\mathrm{R}^{2}=$ & 0,95 & 0,95 & 0,95 \\
\hline & -- & - - - matéria s & ão $\left(g / m^{2}\right)^{3}$ & -ー-ー--- \\
\hline \multirow[t]{4}{*}{ XL 380} & $a=$ & 451 & 581 & 793 \\
\hline & $b=$ & $1,057725 \mathrm{E}+09$ & $4,245993 \mathrm{E}+09$ & 9771679 \\
\hline & $\mathbf{k}=$ & 0,18338803 & 0,1967241 & 0,1375835 \\
\hline & $\mathbf{R}^{2}=$ & 0,99 & 1,011 & 0,99 \\
\hline \multirow[t]{4}{*}{ BR 201} & $a=$ & 493 & 628 & 931 \\
\hline & $\mathbf{b}=$ & $1,053559 E+07$ & $1,63677 \mathrm{E}+09$ & $3,067324 \mathrm{E}+07$ \\
\hline & $\mathbf{k}=$ & 0,1445242 & 0,1943112 & 0,1524528 \\
\hline & $\mathbf{R}^{2}=$ & 0,999 & 1,002 & 0,998 \\
\hline \multirow[t]{4}{*}{ P 3072} & $a=$ & 296 & 422 & 547 \\
\hline & $b=$ & $4,548803 E+09$ & $6,261945 E+09$ & 2192585 \\
\hline & $\mathbf{k}=$ & 0,2075306 & 0,2144771 & 0,1389413 \\
\hline & $\mathbf{R}^{2}=$ & 1,040 & 1,026 & 0,98 \\
\hline
\end{tabular}

1 - Função polinomial quadrática $w=a+b x+c x^{2}$

2.3 - Função logística $w=a /\left(1+b e^{+1}\right)$

Conforme Draper \& Smith (1981), o critério dos quadrados mínimos gera estimativas tendenciosas dos parâmetros de funções não lineares quando o número de pares de pontos é pequeno. Nesses casos, eventualmente, podem ocorrer estimativas de $R^{2}>1$. 
semelhantes. A área foliar cresceu até um determinado estádio, atingiu um valor máximo proximo do início do período de enchimento de grãos e, a partir daí, em consequéncia da senescencia das folhas inferiores, decresceu ate 0 final do ciclo da planta. $O$ processo de senescência no híbrido superprecoce, que se iniciou após o florescimento (ou início do perfodo de enchimento de grãos) foi mais acelerado. Essa característica contribuiu para o menor acúmulo de matéria seca total e do grão, e consequentemente, para os menores rendimentos do híbrido, nas três densidades de cultivo. Aliado a isto, o híbrido superprecoce produziu menor área foliar e apresentou menor ciclo de desenvolvimento. Produziu menos matéria seca total que os outros hibridos em todas as fases de seu ciclo.
Com base em pesquisa do crescimento compensatório e padrôes de partição de carbono, pesquisadores tem sugerido que 6rgãos-dreno na planta competem por uma oferta limitada de carbono assimilado. Essa idéia é consistente com - entendimento de que assimilados são transportados para órgãos-dreno via uma interconexão dos tubos crivados floemáticos, e então, todos os órgãos-dreno tem acesso a um "pool" comum de assimilados em órgãos-fonte. Como em outras situações competitivas, entretanto, - fluxo de saída de assimilados deve ser determinado não apenas pela competição direta por recursos, mas tambem pelos fatores indiretos, tais como aqueles que regulam a taxa de transporte e metabolismo dos tecidos de fonte e de dreno (Setter, 1986).

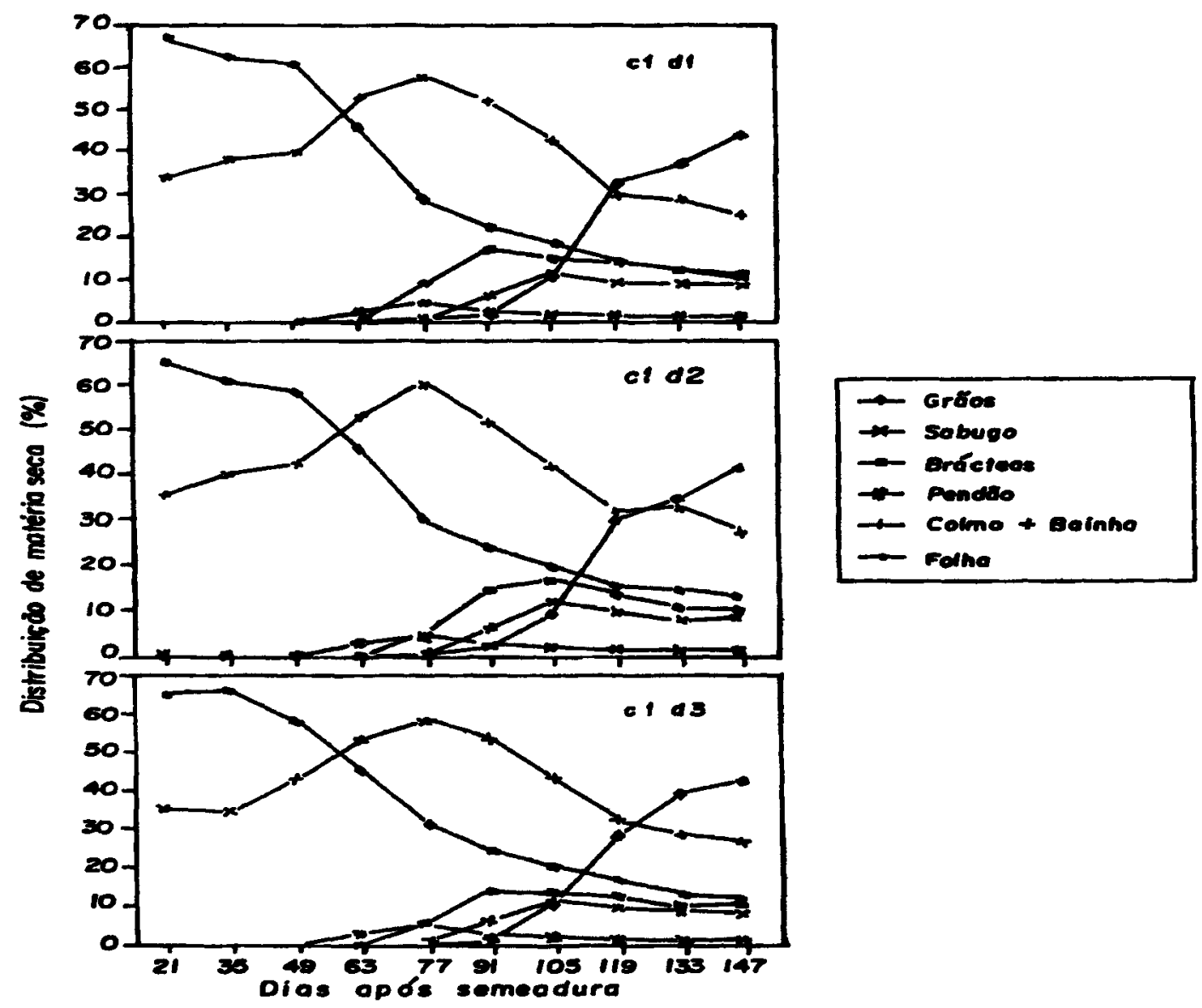

Figura 2a - Distribuição relativa sazonal de matéria seca(com base em $\mathrm{g} / \mathrm{m}$ ) emn hibrido de milho de diferentes ciclos (cl - normal), em três densidades de cultivo (d1 - 33 mil, d2 - 55 mil, d3 - 77 mil plantas/ ha) de safrinha USP/ESALQ, Piracicaba, SP. 1994. 
Os rendimentos de grãos variaram entre os híbridos e entre as densidades e foram significativamente superiores nas maiores densidades de cultivo, para os trés hibridos avaliados (TABELA 5). Rendimento de grãos apresentou correlações positivas altas com o componente número de grâos $/ \mathrm{m}^{2}$ de terreno. Essas duas variáveis apresentaram correlações crescentes $(0,733,0,896$ e 0,918 ) para os híbridos normal, precoce e superprecoce, respectivamente. Número de grãos/ $\mathrm{m}^{2}$ variou entre densidades de.cultivo, assumindo valores significativamente maiores, nas maiores densidades. Rendimento de grãos apresentou correlações negativas altas com o componente
Quantidade total de grãos/espiga, para os híbridos normal e precoce. Quantidade total de grãos/espiga variou significativamente entre hibrido e entre densidade.

A TABELA 6 contém a duração do crescimento e a taxa de crescimento da cultura e dos grãos de milho, segundo os tratamentos utilizados, com Enfase no período de enchimento de grãos. As taxas de crescimento da cultura (TCC) e de grãos (TCG) foram maiores nas densidades maiores, e refletem bem o rendimento dos diferentes híbridos. TCC e TCG maiores corresponderam a maiores rendimentos de grão. As funções logísticas descreveram adequadamente as variações de peso

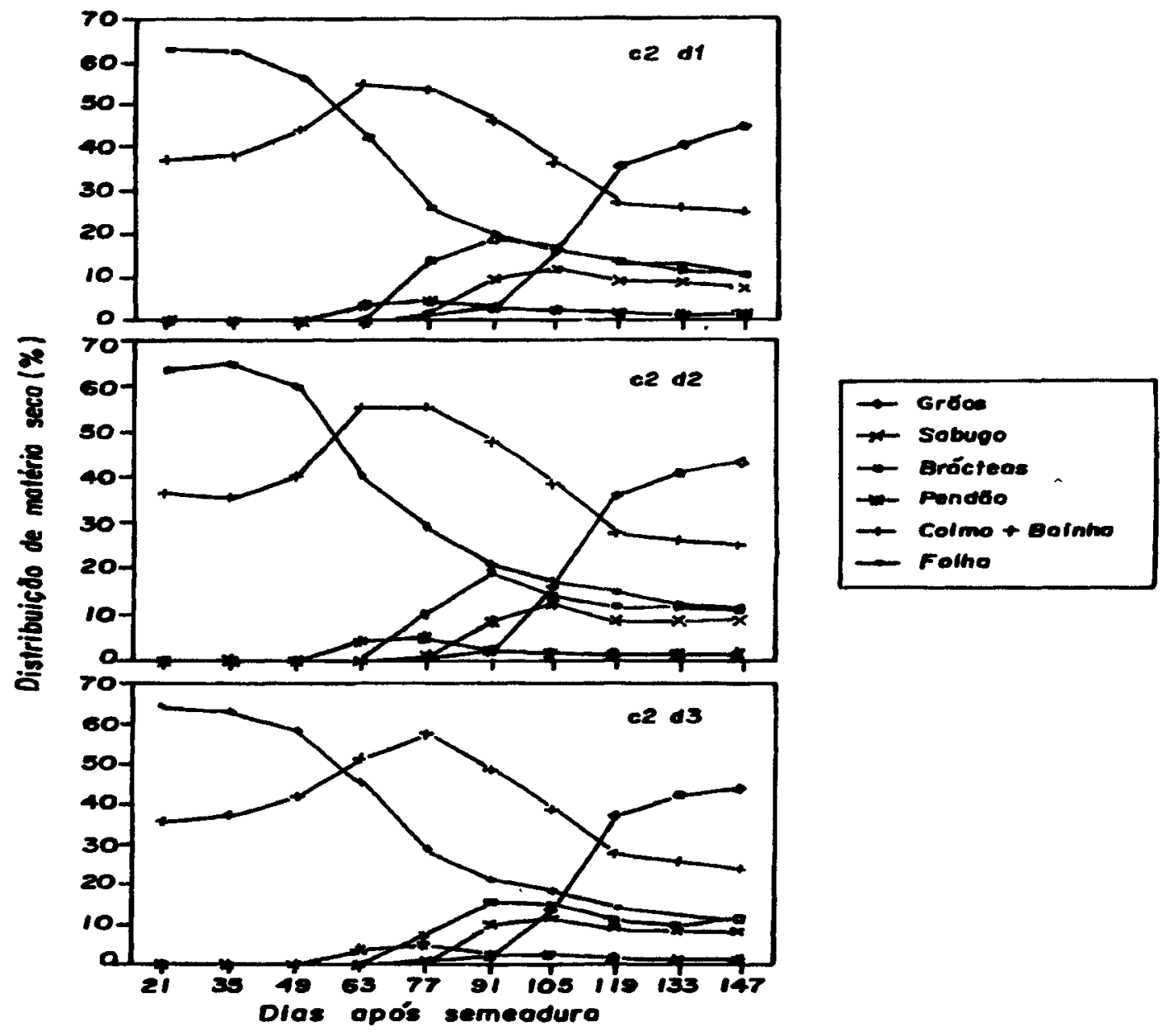

Figura $2 \mathrm{~b}$ - Distribuição relativa sazonal de matéria seca(com base em $\mathrm{g} / \mathrm{m}^{2}$ ) em híbrido de milho de diferentes ciclos (c3 - superprecoce), em três densidades de cultivo (d1 - 33 mil, d2 - 55 mil, d3 - 77 mil plantas/ha) de safrinha USP/ESALQ, Piracicaba, SP. 1994. 
de matéria seca total e do grâo, dos híbridos, nas diferentes densidades.

\section{CONCLusões}

A análise dos dados e a interpretação dos resultados do presente trabalho permitiram concluir:

Para o cultivo do milho de safrinha deve-se dar preferencia a genótipos que tenham larga capacidade de dreno e que acumulem rapidamente matéria seca em seus órgãos, continuando ainda a acumular, paralelamente ao enchimento de grãos, matéria seca total. A redistribuição de assimilados após o início do período de enchimento de grãos é uma caracteristica desejável.

Como essas caracteristicas são afetadas por condições ambientais de cultivo, pesquisas do comportamento de genótipos de milho de ciclos

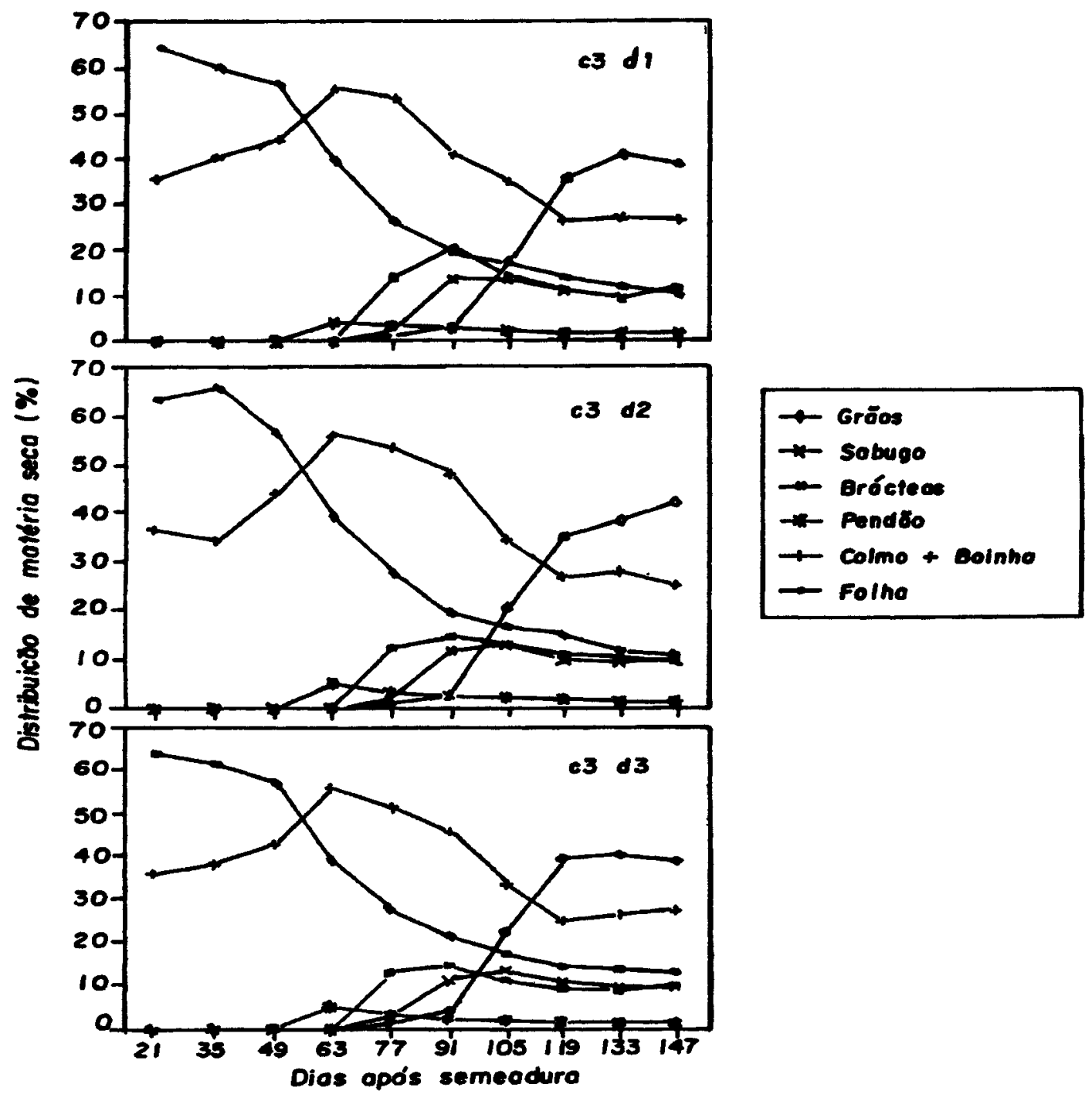

Figura $2 c$ - Distribuição relativa sazonal de matéria seca(com base em $\mathrm{g} / \mathrm{m}^{2}$ ) em híbrido de milho de diferentes ciclos (c3 - precoce), em três densidades de cultivo (d1 - 33 mil, d2 - 55 mil, d3 - 77 mil plantas/ ha) de safrinha USP/ESALQ, Piracicaba, SP. 1994. 
TABELA 5 - Rendimento relativo de grãos (RRG, em kg/ha) e componentes do rendimento de cultivares de milho de diferentes ciclos, em tres densidades de cultivo de safrinha. USP/ESALQ, Piracicaba, SP. 1994.

\begin{tabular}{|c|c|c|c|c|c|c|c|c|}
\hline \multicolumn{2}{|c|}{ Tratamento } & \multirow{2}{*}{$\frac{\text { RRG }}{\%}$} & \multicolumn{6}{|c|}{ Componentes do Rendimento } \\
\hline cultivar & $\begin{array}{c}\text { densidade } \\
\text { (1000 plantas/ha) }\end{array}$ & & $\mathrm{CE}$ & DE & NF $/ E$ & $Q G / F / E$ & QTG /E & $\mathrm{NG} / \mathrm{m}^{2} / \mathrm{T}$ \\
\hline$X L 380$ & $\begin{array}{l}33 \\
55 \\
77\end{array}$ & $\begin{array}{l}151 \text { ef } \\
190 \text { cde }\end{array}$ & $\begin{array}{l}16,9 \text { a } \\
15,5 \text { b }\end{array}$ & $\begin{array}{l}3,2 \mathrm{ab} \\
3,1 \mathrm{~b}\end{array}$ & $\begin{array}{l}13,2 \text { abc } \\
12,1 \mathrm{~d}\end{array}$ & $\begin{array}{l}39,7 \mathrm{a} \\
36,7 \mathrm{abc}\end{array}$ & $\begin{array}{l}522,2 \text { ef } \\
442,9 \text { cde }\end{array}$ & $\begin{array}{l}1741 c \\
2460 b\end{array}$ \\
\hline BR 201 & $\begin{array}{l}77 \\
33 \\
55 \\
77\end{array}$ & $\begin{array}{c}256 \mathrm{~b} \\
160 \mathrm{def} \\
212 \mathrm{c} \\
306 \mathrm{a}\end{array}$ & $\begin{array}{c}14,7 \mathrm{bc} \\
16,0 \mathrm{ab} \\
16,0 \mathrm{ab} \\
14,9 \mathrm{bc}\end{array}$ & $\begin{array}{l}4,0 \mathrm{ab} \\
4,7 \mathrm{a} \\
4,7 \mathrm{a} \\
4,5 \mathrm{ab}\end{array}$ & $\begin{array}{c}12,5 \mathrm{~cd} \\
13,2 \mathrm{abc} \\
13,1 \mathrm{bc} \\
12,0 \mathrm{~d}\end{array}$ & $\begin{array}{l}33,7 \mathrm{~cd} \\
38,5 \mathrm{ab} \\
35,7 \mathrm{bcd} \\
35,9 \mathrm{bcd}\end{array}$ & $\begin{array}{l}419,5 \mathrm{~b} \\
505,2 \text { def } \\
467,6 \mathrm{c} \\
428,9 \mathrm{a}\end{array}$ & $\begin{array}{l}3262 \text { a } \\
1684 \mathrm{c} \\
2597 \mathrm{~b} \\
3335 \mathrm{a}\end{array}$ \\
\hline P 3072 & $\begin{array}{l}33 \\
55 \\
77\end{array}$ & $\begin{array}{l}100 \mathrm{~g} \\
143 \mathrm{f} \\
192 \mathrm{~cd}\end{array}$ & $\begin{array}{l}13,8 \mathrm{~cd} \\
13,2 \mathrm{~d} \\
13,0 \mathrm{~d}\end{array}$ & $\begin{array}{l}4,4 \mathrm{ab} \\
4,5 \mathrm{ab} \\
4,4 \mathrm{ab}\end{array}$ & $\begin{array}{l}14,0 \mathrm{a} \\
13,9 \mathrm{ab} \\
13,9 \mathrm{ab}\end{array}$ & $\begin{array}{l}32,4 \mathrm{de} \\
29,6 \mathrm{e} \\
29,0 \mathrm{e}\end{array}$ & $\begin{array}{l}451,5 \mathrm{~g} \\
411,8 \mathrm{f} \\
405,2 \mathrm{~cd}\end{array}$ & $\begin{array}{l}1505 \mathrm{c} \\
2286 \mathrm{~b} \\
3151 \mathrm{a}\end{array}$ \\
\hline $\mathrm{CV}(\%)$ & & 13,4 & 5,58 & 22,6 & 3,97 & 6,66 & 7,57 & 8,7 \\
\hline
\end{tabular}

Componentes do rendimento (Média de 5 espigas, por tratamento):

CE, comprimento da espiga, $\mathrm{cm}$

DE, diâmetro da espiga, cm

NF/E, número de fileiras por espiga

QG/F/E, quantidade de grãos por fileira por espiga

QTG/E, quantidade total de gräos por espiga

$\mathrm{NG} / \mathrm{m}^{2} / \mathrm{T}$, número de grä́os por metro quadrado de terneno por tratamento (cultivar $x$ densidade)

Na coluna, médias seguidas da mesma letra não diferem entre si, a $5 \%$ de probabilidade, pelo teste de Duncan.

TABELA 6 - Graus-Dia (GD) e taxa de crescimento de cultura e de grãos de cultivares de milho de diferentes ciclos, em três densidades de cultivo de safrinha. USP/ESÁLQ, Piracicaba, SP. 1994.

\begin{tabular}{|c|c|c|c|c|c|}
\hline \multicolumn{2}{|c|}{$\begin{array}{c}\text { Tratamento } \\
\text { cultivardensidade } \\
(1000 \text { plantas } / \mathrm{ha})\end{array}$} & $\frac{\text { PEG(GD) }}{440,76 \text { a }}$ & $\frac{\text { FV(TCC) }}{6,084 \mathrm{c}}$ & $\frac{\text { PEG(TCC) }}{\text { 9,934 cde }}$ & $\frac{\text { PEG(TCG) }}{7,272 \text { de }}$ \\
\hline XL 380 & $\begin{array}{l}33 \\
55 \\
77\end{array}$ & $\begin{array}{l}440,76 \mathrm{a} \\
417,42 \mathrm{a} \\
440,76 \mathrm{a}\end{array}$ & $\begin{array}{c}6,084 \mathrm{c} \\
9,924 \mathrm{ab} \\
11,327 \mathrm{a}\end{array}$ & $\begin{array}{l}9,934 \text { cde } \\
13,230 \text { abc } \\
16,313 \text { bcde }\end{array}$ & $\begin{array}{l}7,272 \text { de } \\
9,701 \text { cd } \\
12,481 \mathrm{~b}\end{array}$ \\
\hline BR 201 & $\begin{array}{l}33 \\
55 \\
77\end{array}$ & $\begin{array}{l}417,42 \mathrm{a} \\
394,08 \mathrm{a} \\
417,42 \mathrm{a}\end{array}$ & $\begin{array}{l}6,876 \mathrm{bc} \\
9,286 \mathrm{ab} \\
12,638 \mathrm{a}\end{array}$ & $\begin{array}{l}11,187 \mathrm{ab} \\
17,300 \mathrm{ab} \\
19,658 \mathrm{a}\end{array}$ & $\begin{array}{l}8,124 \mathrm{~d} \\
11,300 \mathrm{bc} \\
15,540 \mathrm{a}\end{array}$ \\
\hline P 3072 & $\begin{array}{c}33 \\
55 \\
77\end{array}$ & $\begin{array}{l}417,41 \mathrm{a} \\
417,42 \mathrm{a} \\
417,42 \mathrm{a}\end{array}$ & $\begin{array}{l}5,876 \mathrm{c} \\
7,952 \mathrm{bc} \\
9,943 \mathrm{ab}\end{array}$ & $\begin{array}{c}5,263 \mathrm{e} \\
7,405 \mathrm{de} \\
11,952 \text { bcde }\end{array}$ & $\begin{array}{l}5,047 \mathrm{e} \\
7,147 \mathrm{de} \\
9,637 \mathrm{~cd}\end{array}$ \\
\hline
\end{tabular}

PEG, Período de enchimento de grios

GD, Graus-Dia acumulados no periodo

GD na fase vegetativa $=891,97$ unidades térmicas

FV, Fase vegetativa (da semeadura até o início do PEG)

TCC, Taxa de crescimento da cultura, em $\mathrm{g} / \mathrm{m}^{2}$ dia

TCG, Taxa de crescimento de grióos, $\mathrm{em} \mathrm{g} / \mathrm{m}^{2}$ dia

Na coluna, médias seguidas da mesma letra não diferem entre si, a $5 \%$ de probabilidade, pelo teste de Duncan. 
diferentes em multilocais deverão responder sobre épocas adequadas de semeadura, visando maior rendimento de grãos.

\section{REFERÊNCIAS BIBLIOGRÁFICAS}

ALLISON, J.C.S.; WATSON, D.J. The production and distribution of dry matter in maize after flowering. Annals of Botany, v.30, n. 119, p.365-81, 1966.

ASPIAZÚ, C. Comparison of several methods of heat unit calculation for corn (Zea mays L.) Ames, 1971 . 148 p. Thesis (M.S.)-Iowa State University.

DAYNARD, T.B.; TANNER, J.W.; DUNCAN, W.G. Duration of the grain filling period and its relation to grain yield in corn (Zea mays L.). Crop Science, v.11, n.1, p.45-8, 1971.

DONALD, C.M.; HAMBLIN, J. The biological yield and harvest index of cereals as agronomic and plant breeding criteria. Advances in Agronomy, v.28, p.361-405, 1976.

DRAPER, N.R.; SMITH, H. Applied regression analysis. 2. ed. New York: J. Wiley, 1981. 709 p.

DURÃES, F.O.M.; MAGALHÃES, P.C.; OLIVEIRA, A.C.; FANCELLI, A.L.; COSTA, J.D. Partição de fitomassa e limitações do rendimento de milho (Zea mays L.) relacionadas com a fonte-dreno. In: CONGRESSO BRASILEIRO DE FISIOLOGIA VEGETAL, 4., Fortaleza, 1993. Resumos. Revista Brasileira de Fisiologia Vegetal, v.5, n.1, p.90, 1993.

GERAGE, A.C.; BIANCO, R. A produção de milho na "safrinha". Informe Agropecuário, v.14, n.164, p.39-44, 1987.

GOLDSWORTHY, P.R.; COLEGROVE, M. Growth and yield of highland maize in Mexico. Journal of Agricultural Science, v.83, p.213-21, 1974.
GOLDSWORTHY, P.R.; PALMER, A.F.E.; SPERLING, D.W. Growth and yield of lowland tropical maize in Mexico. Journal of Agriculture Science, v.83, p.223$30,1974$.

HANWAY, J.J.; RUSSELL, W.A. Dry-matter accumulation in corn (Zea mays L.) plants: comparisons among single-cross hybrids. Agronomy Journal, v.61, n.6, p.947-51, 1969.

SETTER, T.L. Partitioning of carbon among competing sinks. In: ANNUAL PENNSYLVANIA STATE SYMPOSIUM IN PLANT PHYSIOLOGY, 1., Pennsylvania, 1986. Proceedings. Rockville: American Society of Plant Physiologists, 1986. p.372.

TOLLENAAR, M. Sink-source relationships during reproductive development in maize. a review. Maydica, v.22, p.49-75, 1977.

TOLLENAAR, M.; DAYNARD, T.B. Relationship between assimilate source and reproductive sink in maize grown in a short season environment. Agronomy Journal, v.70, n.2, p.219-23, 1977.

VIDAL TORRADO, P.; SPAROVEK, G. Mapa pedologico detalhado do Campus "Luiz de Queiroz", Universidade de Săo Paulo. (escala 1:10.000). Piracicaba: ESALQ, 1993.

WILSON, J.H.; CLOWES, M. St. J.; ALLISON, J.C.S. Growth and yield of maize ate different altitudes in Rhodesia. Annals of Applied Biology, v.73, n.1, p.7784, 1973.

Recebido para publicação em 26.07.95

Aceito para publicação em 14.08.95 